\title{
ANALISIS AERODINAMIK PADA BODI KENDARAAN LISTRIK TYPE CITYCAR UNTUK LINGKUNGAN KAMPUS
}

\author{
Ari Ekoprianto
}

\begin{abstract}
ABSTRAK
Salah satu upaya yang dilakukan untuk menekan pemborosan energi pada suatu kendaraan adalah dengan mendesain bentuk kendaraan yang aerodinamis. Penelitian ini bertujuan untuk melakukan analisa aerodinamik pada konsep rancangan bodi kendaraan roda 4 bertenaga listrik berkapasitas 4 (empat) orang yang memiliki gaya hambat udara (drag) terendah. Bagian kendaraan yang dianalisa adalah sudut kap mesin (bonnet), sudut kaca depan (windshield), kelengkungan atap dan sudut bagian belakang kendaraan. Pemilihan kombinasi bagian yang menghasilkan gaya hambat udara (drag) terendah menggunakan metode ortogonal selanjutnya bentuk tersebut dibuat model digital untuk selanjutnya dianalisa dengan menggunakan perangkat lunak Computational Fluid Dynamics (CFD). Disimulasikan model kendaraan listrik berjalan pada kecepatan $30 \mathrm{~km} / \mathrm{h}, 35 \mathrm{~km} / \mathrm{h}, 40 \mathrm{~km} / \mathrm{h}, 45 \mathrm{~km} / \mathrm{kam}$ dan $50 \mathrm{~km} / \mathrm{h}$. Dimensi optimal untuk menghasilkan gaya hambat (drag) terendah adalah kap mesin dengan sudut kemiringan 10 derajat, kaca depan (windshield) dengan sudut kemiringan 65 derajat, konveksitas atap 1/10 dan sudut kemiringan bagian belakang kendaraan 10 derajat, pada kecepatan $50 \mathrm{~km} / \mathrm{jam}$ menghasilkan gaya hambatan sebesar $297.22 \mathrm{~kg} \cdot \mathrm{m} / \mathrm{s}^{2}$.
\end{abstract}

Kata kunci: Aerodinamik, kendaraan listrik, CFD

\section{Pendahuluan}

Salah satu upaya yang dilakukan untuk menekan pemborosan energi pada suatu kendaraan adalah dengan mendesain bentuk kendaraan yang aerodinamis. Gambar 1.1 menunjukkan deskripsi penggunaan energi pada suatu kendaraan bertenaga listrik. Faktor bentuk kendaraan menggunakan $29 \%$ energi listrik, konsumsi energi yang sangat banyak ini menarik para engineer untuk mendesain kendaraan dengan bentuk yang aerodinamis dan meminimalkan tahanan udara (drag).

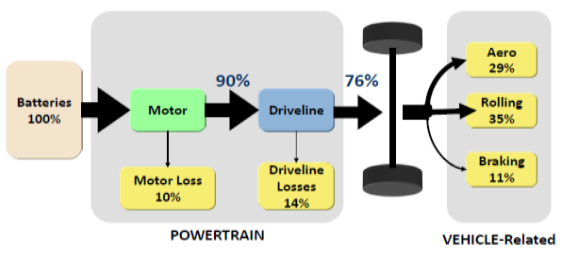

Gambar 1. Penggunaan energi pada kendaraan listrik

Berdasarkan latar belakang tersebut maka pertanyaan utama yang ingin didapat jawabannya adalah desain bodi kendaraan yang memiliki gaya hambat udara (drag) terendah sehingga dapat dicapai efisiensi penggunaan energi tertinggi.

\section{Tinjauan Pustaka}

Aerodinamika berasal dari dua buah kata yaitu Aero berasal dari bahasa Yunani yang berarti udara dan Dinamika yang diartikan sebagai kekuatan atau tenaga. Jadi Aerodinamika dapat diartikan sebagai suatu cabang ilmu pengetahuan yang mempelajari interaksi antara aliran fluida dengan bendabenda solid yang bergerak secara relatif di dalam aliran tersebut.

Pertimbangan aerodinamika adalah penting dalam desain kendaraan darat. Kendaraan yang bergerak melalui media udara akan mengalami gaya-gaya aerodinamis. Penyebab utama dari timbulnya gaya-gaya aerodinamis pada kendaraan adalah:

1. Adanya distribusi tekanan pada permukaan bodi kendaraan yang akan bekerja pada arah normal pada permukaan kendaraan.

2. Adanya distribusi tegangan geser pada permukaan bodi kendaraan yang akan bekerja pada arah tangesial terhadap permukaan kendaraan. 
Gaya drag tekanan atau sering disebut drag tekanan adalah bagian drag yang lansung disebabkan oleh tekanan, $\mathrm{P}$ pada sebuah benda. Drag tekanan adalah fungsi dari besarnya tekanan dan orientasi arah elemen permukaan dimana gaya tekanan tersebut bekerja.

Gaya hambat (drag) total terdiri dari beberapa gaya hambat yaitu:

\section{Hambatan bentuk}

Gaya hambat yang disebabkan oleh adanya gradien tekanan (pressure drag) dan adanya gesekan (friction drag).

Bentuk bodi kendaraan yang kompleks menyebabkan terjadinya distribusi tekanan di sepanjang permukaan kendaraan tersebut. Selain itu karena aliran udara bersifat viscous maka timbul tekanan geser di sepanjang permukaan kendaraan. Dengan adanya perbedaan tekanan antara bagian depan kendaraan dan bagian belakang kendaraan, dimana tekanan positif bekerja pada bagian depan kendaraan dan tekanan negatif di bagian belakang kendaraan sehingga menyebabkan timbulnya gaya drag yang bekerja berlawanan dengan arah gerak kendaraan.

\section{Hambatan pusaran}

Karena adanya perbedaan tekanan antara bagian atas dan bagian bawah kendaraan, menyebabkan timbulnya gesekan aliran udara dan permukaan bawah menuju ke permukaan atas kendaraan yang berupa pusaran (vortex). Timbulnya vortex pada kendaraan juga akan menghambat gerak laju kendaraan yang disebabkan adanya pengaruh gaya angkat vertikal pada bodi mobil yang sedang bergerak horizontal.

\section{Hambatan Tonjolan}

Gaya hambat yang disebabkan oleh adanya tonjolan profil tertentu pada bagian permukaan bodi kendaraan seperti kaca spion, pegangan pintu, antena dan aksesori lainnya.

\section{Hambatan aliran dalam}

Gaya hambat oleh aliran udara yang mengalir melalui sistem pendingin mesin yaitu radiator.

Pada kenyataannya hanya hambatan bentuk dan hambatan pusar yang paling besar pengaruhnya terhadap gaya hambat secara keseluruhan. Gaya hambatan tersebut adalah sebagai fungsi dari kecepatan kuadrat.

Secara umum perumusan gaya hambat angin adalah:

$\mathrm{F}_{\mathrm{d}}=\frac{1}{2} \cdot \rho \cdot \mathrm{C}_{\mathrm{d}} \cdot \mathrm{A}_{\mathrm{f}} \cdot \mathrm{V}_{\mathrm{a}}^{2}$

Dimana :

$\begin{array}{lll}\mathrm{F}_{\mathrm{d}} & =\text { Gaya hambat } & (\mathrm{N}) \\ \rho & =\text { Masa jenis Fluida } & \left(\mathrm{Kg} / \mathrm{m}^{3}\right) \\ \mathrm{C}_{\mathrm{d}} & =\text { Koefisien drag } \\ \mathrm{A}_{\mathrm{f}} & \text { = Luas Frontal kendaraan }\left(\mathrm{m}^{2}\right) \\ \mathrm{V}_{\mathrm{a}} & =\text { Kecepatan fluida } \quad(\mathrm{m} / \mathrm{s})\end{array}$

Gambar 2. menunjukkan hasil pengujian pengaruh kemiringan kap mesin (bonnet) dan kaca depan (windshield) terhadap drag yang dilakukan oleh Carr [..]

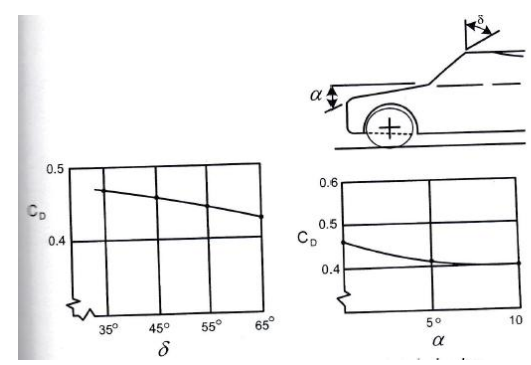

Gambar 2. Efek kemiringan kap mesin dan kaca depan terhadap drag

Perbaikan aerodinamik pada bagian atap dari kendaraan dapat dilakukan dengan mendesain atap dengan bentuk konvex, aliran udara akan mudah mengalir ke belakang. Jika konveksitas diperbesar, koefisien drag dapat diperkecil. Jika bentuk konvex didesain sehingga menyebabkan pertambahan luas frontal area, maka aerodinamik drag juga meningkat. Jika tinggi atap asli dibiarkan konstan maka kaca depan dan belakang harus dibuat melengkung menuju countour sehingga efek konveksitas dapat dicapai. 


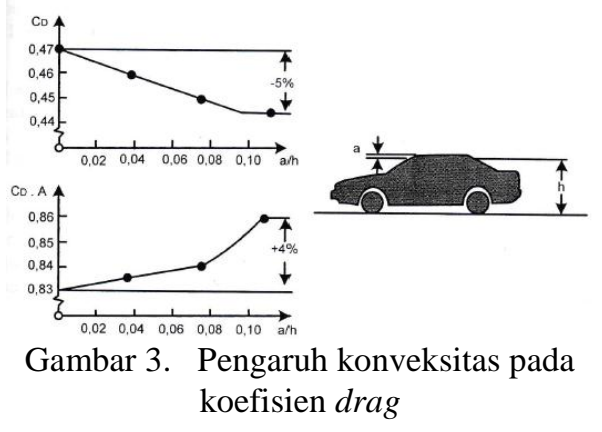

Bentuk bagian belakang kendaraan dapat dibedakan menjadi 3 jenis yaitu squareback (van), fastback, dan notchback (saloon). Separasi yang terjadi pada bentuk squareback pada umumnya dimulai dari titik ujung belakang kendaraan sedangkan pada bentuk fastback dan notchback titik separasi dimulai lebih bawah tergantung desain kemiringan kaca belakang.
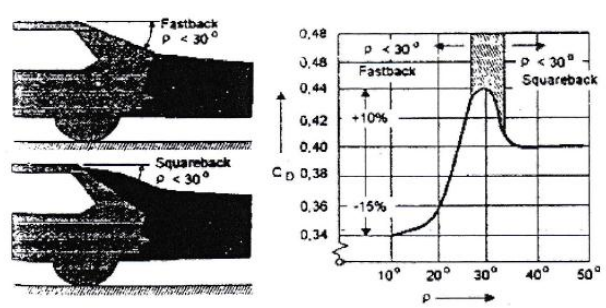

Gambar 4. Pengaruh kemiringan bagian belakang terhadap drag

Perbaikan aerodinamik dapat dilakukan dengan desain taper pada bagian belakang kendaraan yaitu dengan pembentukan ujung lancip pada bagasi.

Pada bentuk fastback besarnya drag terhadap kemiringan bagian belakang selain dipengaruhi oleh besarnya wake juga dipengaruhi oleh besarnya aliran vortex yang terjadi pada bagian belakang kendaraan.

Pada bagian belakang yang mempunyai kemiringan antara 15 derajat sampai dengan 35 derajat besarnya drag dan lift sangat bervariasi kerena adanya pengaruh vortex yang cukup besar pada kemiringan tersebut.
Computational Fluid Dynamics atau biasa disingkat CFD baru dimulai penggunaannya pada awal tahun 1970 an merupakan kombinasi dari persamaan-persamaan fisika, matematika numerik dan ilmu komputer untuk mensimulasi aliran fluida. Pada saat ini metodologi CFD semakin banyak digunakan dalam bidang penerbangan, mesin turbo, kendaraan dan desain kapal laut.

Program Computational Fluid Dynamics (CFD) mensimulasikan prediksi kualitatif dan kadang juga kuantitatif aliran fluida melalui;

- Model Matematika (Partial Differential Equation)

- Metode Numerik (deskrit dan teknik pemecahan masalah)

- Perangkat Lunak (utilitas pra dan pasca proses, pemecahan persoalan)

CFD memungkinkan peneliti dan ahli teknik memperagakan "numerical experiment" dalam bentuk simulasi komputer dalam laboratorium virtual. Simulasi numerik aliran fluida akan memungkinkan misalnya;

- Arsitek merancang lingkungan tempat tinggal yang nyaman dan aman

- Perancang kendaraan meningkatkan karakteristik aerodinamik kendaraannya

- Ahli klimatologi dapat memprediksi cuaca dan memberikan peringatan dini terjadinya bencana

\section{Metodologi Penelitian}

Dipilih parameter sudut kap mesin, sudut kaca depan, konvektifitas dan sudut bagian kendaraan selanjutnya dihitung besar hambatan aerodinamik (drag) nya. Desain diseleksi menggunakan Matriks Ortogonal, yaitu suatu matriks yang elemen-elemennya disusun menurut baris dan kolom. Kolom merupakan faktor yang dapat diubah dalam eksperimen. Baris merupakan kombinasi level dari faktor dalam eksperimen.

Kombinasi yang paling rendah hambatan (drag) dibuat gambar modelnya dan kemudian disimulasikan dengan CFD. 


\section{Perhitungan dan Analisis}

Menggunakan metoda ortogonal $4^{2}$ ditentukan kombinasi bentuk paling kecil gaya hambatnya. Adapun variabel yang dipilih adalah:

1. Kemiringan Kap Mesin

$$
\begin{array}{ll}
\mathrm{A} 1=5 \text { derajat } & \mathrm{C}_{\mathrm{D}}=0.42 \\
\mathrm{~A} 2=10 \text { derajat } & \mathrm{C}_{\mathrm{D}}=0.4
\end{array}
$$

2. Kemiringan $\mathrm{Kaca} /$ windshield

$$
\begin{array}{ll}
\mathrm{B} 1=55 \text { derajat } & \mathrm{C}_{\mathrm{D}}=0.45 \\
\mathrm{~B} 2=65 \text { derajat } & C_{\mathrm{D}}=0.42
\end{array}
$$

3. Kelengkungan `Atap

$$
\begin{array}{ll}
\mathrm{C} 1=0.1 & \mathrm{C}_{\mathrm{D}}=0.445 \\
\mathrm{C} 2=0.08 & \mathrm{C}_{\mathrm{D}}=0.45
\end{array}
$$

4. Kemiringan bagian belakang

$$
\begin{aligned}
& \mathrm{D} 1=10 \text { derajat } \mathrm{C}_{\mathrm{D}}=0.34 \\
& \text { D2 = } 20 \text { derajat } C_{D}=0.36
\end{aligned}
$$

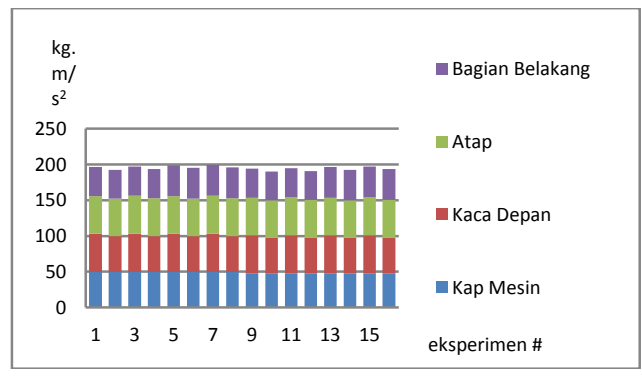

Grafik 1. Daya Hambat Kendaraan pada kecepatan $40 \mathrm{~km} / \mathrm{h}$

Dari grafik 1. terlihat eksperimen nomer 10 merupakan kombinasi yang mempunyai daya hambat terendah yaitu sebesar $190.22 \mathrm{~kg} . \mathrm{m} / \mathrm{s}^{2}$

Dari 5 percobaan dengan kecepatan yang berbeda-beda masing-masing $30 \mathrm{~km} / \mathrm{h}$, $35 \mathrm{~km} / \mathrm{h}, 40 \mathrm{~km} / \mathrm{h}, 45 \mathrm{~km} / \mathrm{h}$ dan $50 \mathrm{~km} / \mathrm{h}$ eksperimen nomer 10 memberikan hasil gaya hambat terendah. Eksperimen nomer 10 ini adalah kombinasi A.2, B.2, C.1 dan D.1 yaitu Kap mesin dengan sudut 10 derajat, Kaca depan dengan sudut 65 derajat, konveksitas 0.1 dan sudut bagian belakang sebesar 10 derajat.

Kombinasi A.2, B.2, C.1 dan D.1 yaitu sudut kap mesin 10 derajat, kemiringan kaca depan 65 derajat, kelengkungan atap 0.1 dan kemiringan belakang 10 derajat dipilih untuk diuji dengan menggunakan CFD pada beberapa kombinasi kecepatan yaitu $50 \mathrm{~km} / \mathrm{h}$, $45 \mathrm{~km} / \mathrm{h}, 40 \mathrm{~km} / \mathrm{h} 35 \mathrm{~km} / \mathrm{h}$ dan $30 \mathrm{~km} / \mathrm{h}$

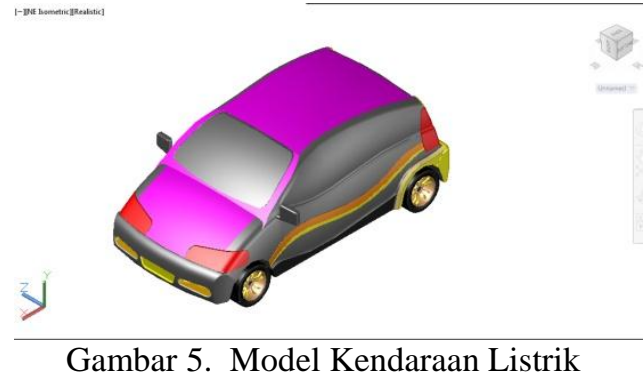

Dengan menggunakan bantuan software Computational Fluid Dynamic (CFD) dapat dilihat laju fluida yang mengalir pada suatu benda dalam hal ini model kendaraan yang dirancang. Disimulasikan model kendaraan listrik berjalan pada kecepatan $30 \mathrm{~km} / \mathrm{h}, 35 \mathrm{~km} / \mathrm{h}, 40 \mathrm{~km} / \mathrm{h}, 45$ $\mathrm{km} / \mathrm{h}$ dan $50 \mathrm{~km} / \mathrm{h}$. Hasilnya adalah sebagai berikut:

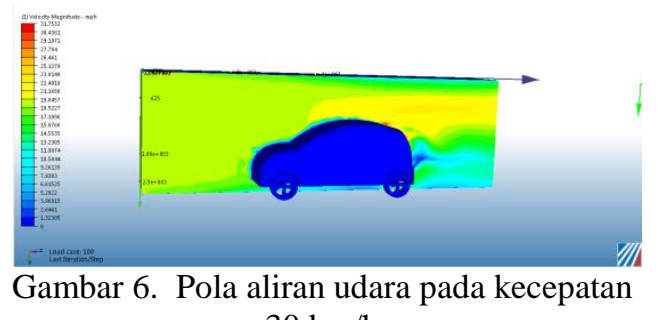
$30 \mathrm{~km} / \mathrm{h}$

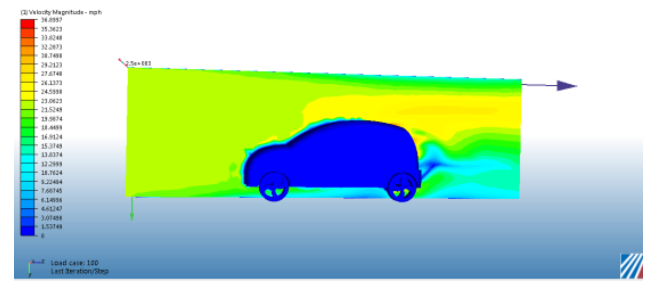

Gambar 7. Pola aliran udara pada kecepatan $35 \mathrm{~km} / \mathrm{h}$

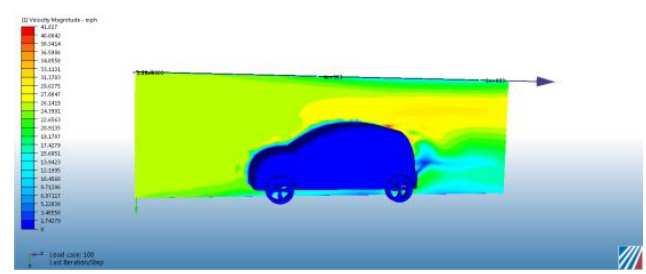

Gambar 8. Pola aliran udara pada kecepatan $40 \mathrm{~km} / \mathrm{h}$ 


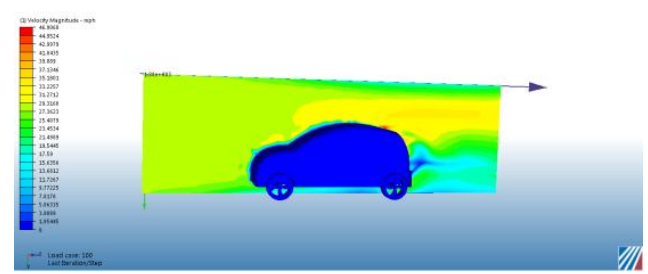

Gambar 9. Pola aliran udara pada kecepatan $45 \mathrm{~km} / \mathrm{h}$

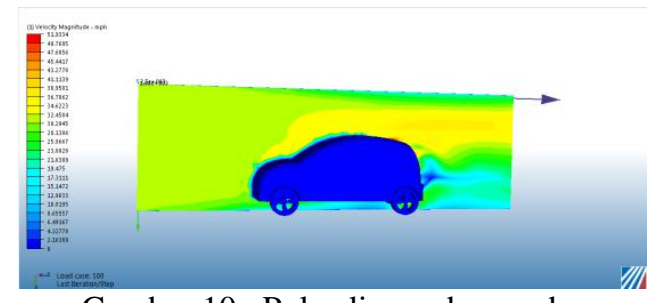

Gambar 10. Pola aliran udara pada kecepatan $50 \mathrm{~km} / \mathrm{h}$

\section{Kesimpulan}

Dari hasil analisis aerodinamik pada bodi kendaraan listrik tipe citycar untuk lingkungan kampus dapat disimpulkan bahwa:

Dimensi optimal untuk menghasilkan gaya hambat (drag) terendah adalah kap mesin dengan sudut kemiringan 10 derajat, kaca depan (windshield) dengan sudut kemiringan 65 derajat, konveksitas atap 1/10 dan sudut kemiringan bagian belakang kendaraan 10 derajat, pada kecepatan 50 $\mathrm{km} / \mathrm{jam}$ menghasilkan gaya hambatan sebesar $297.22 \mathrm{~kg} . \mathrm{m} / \mathrm{s}^{2}$.

Gaya hambatan terbesar pada kecepatan $50 \mathrm{~km} / \mathrm{jam}$ yaitu $311.11 \mathrm{~kg} . \mathrm{m} / \mathrm{s}^{2}$ dapat terjadi pada konfigurasi kap mesin dengan sudut kemiringan 5 derajat, kaca depan (windshield) dengan sudut kemiringan 55 derajat, konveksitas atap 0.08 dan sudut kemiringan bagian belakang kendaraan 20 derajat.

Konsep bodi kendaraan dengan kap mesin dengan sudut kemiringan 10 derajat, kaca depan (windshield) dengan sudut kemiringan 65 derajat, konveksitas atap 1/10 dan sudut kemiringan bagian belakang kendaraan 10 derajat dianallisa menggunakan Computational Fluid Dynamic (CFD) dengan kecepatan $30 \mathrm{~km} / \mathrm{jam}, 35$ $\mathrm{km} / \mathrm{jam}, 40 \mathrm{~km} / \mathrm{jam}, 45 \mathrm{~km} / \mathrm{jam}$ dan 50 $\mathrm{km} / \mathrm{jam}$. Terlihat pada tiap tingkat kecepatan aliran udara dapat melalui permukaan bodi kendaraan dengan lancar. Tidak terdeteksi adanya perlambatan kecepatan aliran udara pada bagian depan kendaraan. Terjadi perlambatan kecepatan aliran udara yang ditunjukan dengan warna biru pada permukaan bodi kendaraan yang dapat dikategorikan wajar karena adanya gesekan antara udara dengan permukaan bodi kendaraan.

Indikasi kecepatan aliran udara yang lebih lambat dari pada kecepatan yang diberikan terjadi pada bagian belakang kendaraan digambarkan dengan warna biru. Kecepatan rendah pada bagian ini menimbulkan tekanan rendah mmemberikan efek gaya yang berlawanan dengan arah kendaraan. Fenomena ini dibuktikan pada pengujian tekanan statis (static pressure), terjadi tekanan yang lebih rendah pada bagian belakang kendaraan digambarkan dengan warna hijau tua nilai tekanan statis dibagian ini antara -90.6 Pa sampai dengan -53.34 Pa.

\section{Saran}

Analisis aerodinamik pada bodi kendaraan listrik tipe citycar untuk lingkungan kampus dapat dilanjutkan dan dikembangkan secara spesifik di bagian belakang kendaraan berupa aplikasi alat tambahan berupa rear spoiler untuk mengurangi gaya hambat dibagian ini.

Pembuatan model kendaraan yang selanjutnya diuji melalui terowongan angin akan memberikan pemahaman lebih jauh mengenai gaya hambat yang terjadi.

\section{Daftar Pustaka}

1. Budyi Suswanto dan Nurida Finahari. 2013, Studi Pengaruh Model Mobil dan Variasi Kecepatan Angin Terhadap Gaya Drag, Widya Teknika Vol.20 No.1 : 14-19.

2. Bruce R, Munson, Donald F. Young, Theodore H. Okiishi and Wade W. Huebsch, 2009, Fundamentals of Fluid Mechanics, John Wiley \& Sons, Inc.

3. D. Ramasamy, K. Kadirgama, A.K. Amirruddin and M.Y. Taib, 2010, A Vehicle Body Drag Analysis, Using Computational Fluid Dynamics, National Conference in Mechanical Engineering Research and Postgraduate Students: 342-353 
4. Dr. Herminarto Sf dan Gunadi, S.Pd. 2004, Perancangan Bodi Kendaraan, Jurusan Pendidikan Teknik, Fakultas Teknik UNY.

5. Prof. Ir. I Nyoman Sutantra, M.Sc.,Ph.D. dan Dr. Ir. Bambang Sampurno, MT. 2010, Teknologi Otomotif, Penerbit Guna Widya, Surabaya, Indonesia.

6. Soejanto, Irwan, 2009, Desain Eksperimen dengan Metode Taguchi, Graha Ilmu.

7. J. Brazek, 2001, Computational Fluid Dynamics: Principle and Application. Alstom Power Ltd. Baden-Daetwil, Switzerland.

8. Klaus A, Hoffmann and Steve T. Chiang, 2000, Computational Fluid Dynamics volume I, Engineering Educations System, Wichita, Kansas, USA.

9. Kogilan A/L Govindasamy, 2009, Design and Analysis of a Rear Wheel Cover for a Car using Computational Fluid Dynamic (CFD), Faculty of Mechanical Engineering Universiti Malaysia Pahang.

10. Li-Xin Guo, Yi-Min dan Wei-Jun Shen. 2011. Simulation Analisys of Aerodynamics Characteristics of Different Two-Dimensional Automobile Shape. Journal of Computer Vol. 6. No. 5: 999-1005.

11. Lorenzo Morello, Lorenzo Rosti Rossini, Giuseppe Pia and Andrea Tonoli, 2011, The Automotive Body, volume I: Component Design, Springer.

12. Lorenzo Morello, Lorenzo Rosti Rossini, Giuseppe Pia and Andrea Tonoli, 2011, The Automotive Body, volume II: System Design, Springer 